\title{
Closed-loop control of a polymerisation plant using production performance indicators (PIs)
}

\author{
S. Zorzut ${ }^{\mathrm{a} *}$, V. Jovan ${ }^{\mathrm{a}}$, D. Gradišar ${ }^{\mathrm{a}}$ and G. Mušič ${ }^{\mathrm{b}}$ \\ ${ }^{a}$ Jožef Stefan Institute, Jamova 39, 1000 Ljubljana, Slovenia, ${ }^{b}$ Faculty of Electrical Engineering, University of Ljubljana, Tržaška \\ 25, 1000 Ljubljana, Slovenia
}

(Received 23 March 2007; final version received 7 March 2009)

\begin{abstract}
The synthesis of plant-wide control structures is recognised as one of the most important production-management design problems in the process industries. This article proposes a closed-loop control structure utilising production performance indicators ( $\mathrm{pPIs}$ ) as a possible solution to simplify this problem. pPIs represent the translation of operating objectives, such as the minimisation of production costs, to a set of measurable variables that can then be used in a feedback control. The idea of closed-loop control at the production-management level using pPIs as referenced controlled variables was implemented on the procedural model of a production process for a polymerisation plant, and two types of controllers were tested: an experimental controller based on look-up tables, and an advanced model predictive controller (MPC). Preliminary results show the usefulness of the proposed methodology.
\end{abstract}

Keywords: production performance indicators; production management; decision-support systems; closed-loop control; model predictive controller

\section{Introduction}

Competitiveness in the global economy has changed the basic method of production from planned production to order-driven production. This has introduced new demands related to flexible production, and increased production efficiency, fast responses to customer demands, and a high and uniform quality of products and services (Holt 1999, Dangelmaier et al. 2005). Nowadays, an enterprise management relies on an online estimation of the current state, efficient decision making and the appropriate execution of decisions (Kaplan and Norton 1992, Lee and Lai 1997, Folan and Brown 2005). In this investigation an important role is given to the interconnection and coordination of various management activities (related to business organisation and production), as well as to the computer support and information support of these activities.

The demands for efficient and flexible production have established the importance of an autonomous production-management level acting as a kind of interface between the requests from the businessmanagement level and the factory-floor production control, as presented in Figure 1 (Anthony 1965, Hales 1989, Jovan et al. 1998). At the productionmanagement level at least two essential activities are performed: (i) the transformation of a company's objectives into results and (ii) the optimisation of production. To fulfil these two basic tasks successfully, a production manager's decisions must rely on accurate and online information.

Discrete and process manufacturing are terms that are often used to describe the nature of manufacturing operations where the process industry has several specifics compared with discrete industry that make it both complex and uncertain (Taylor et al. 1981, Jovan et al. 1998). The complexity arises primarily from the required linking of various sub-processes, each of which affects the quality of the final product. Each subprocess requires the maintenance of a certain number of process parameters, i.e. pressure, temperature, flow, viscosity, etc., which leads to a large number of operation-level sensors, actuators, controllers and programmable controllers that must operate both safely and reliably. The uncertainty of the process industry is expressed above all in product quality. Both uncertainty and complexity have a great influence on production management in industries of this type. The main problems regarding process control and the production manager's decisionmaking process are how to extract the relevant information from huge amounts of disposable production data for the correct decision-making and how to design a plant-wide production-control system that is capable of maintaining near-optimal production

\footnotetext{
*Corresponding author. Email: dejan.gradisar@ijs.si
} 


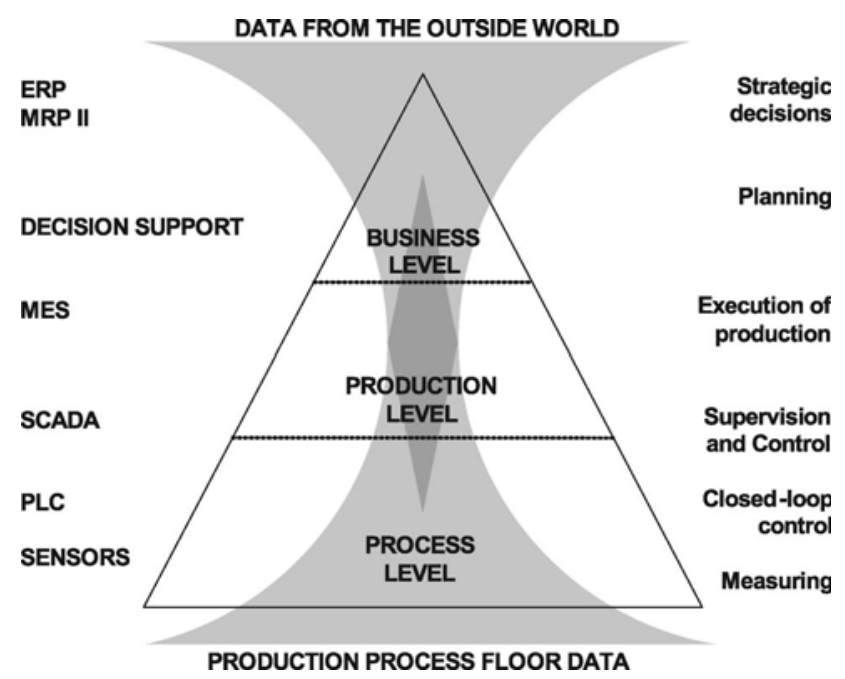

Figure 1. Data flow between business-, production- and process-management levels.

and of eliminating a production manager's/operator's subjective assessments.

Forza and Salvador (2001) discuss the need for information flow and redistribution of management responsibility among all the entities in the management structure in order to achieve an efficient production. The authors also claim that the management subjects, e.g. the production manager, must have beside the knowledge about production also the relevant and upto-date information about the current production and quality of final products. The introduction of performance indicators (PIs) technique is a possible solution to overcome the problem of huge amount of production data and unbalanced realisation of economical, technological, safety, and other production goals. According to Fortuin (1988), PIs 'provide management with a tool to compare actual results with a pre-set target and to measure the extent of any deviation'. A PI can also be defined as 'a variable that quantitatively expresses the effectiveness or efficiency, or both, of a partial or a whole process, or a system, against a given norm or target' (Lohman et al. 2004).

The concept of PIs can take many forms. Neely et al. (1995) used more general terms: performance measures (PMs) and the performance measurement system (PMS). In this literature review, PMs that are related to quality, time, costs and flexibility are presented. Folan and Brown (2005) have presented the concept of evolution from PM to structural and procedural PM frameworks. PMS is the union of these two frameworks into one system (e.g. BSC, Business Process Reengineering BPR). Bourne et al. (2000) suggest that the implementation of the PMS, based on PIs, should be divided into three main phases: (i) the design of the PIs (ii) the implementation of the PIs and (iii) the use of the PIs. The implemented PMS should also include a process for periodically reviewing and revising the complete set of PIs. This should be done to coincide with the changes in the competitive environment, the strategic direction or organisation and the structure of the production processes (Veleva and Ellenbecker 2001). There are many other methods for defining and implementing PIs in production. In Ghalayini et al. (1996) an integrated dynamic performance measurement system (IDPMS) that integrates the management, the process-improvement teams and the factory shop floor is presented. Suwignjo et al. (2000) developed quantitative models for PMS (QMPMS) that can be used to identify the factors affecting performance and their relationships, structure them hierarchically, quantify the effect of the factors on performance, and express them quantitatively. Another method to design and establish a PI system is defined with ECOGRAI (Tatsiopoulos and Panayiotou 2000).

Once the production Performance Indicators (further on pPIs) are defined it is necessary to incorporate them into production-management system. pPIs can be utilised in a production decision support system (DSS), which helps the production manager to estimate how well the production strategy and goals are attained and what should be done to improve the results. In this paper another approach is presented, where pPIs are used as referenced, controlled variables and are integrated directly into the plant-wide closed-loop control system. The proposed production control system is divided into two hierarchical layers: the optimisation layer, where production costs are optimised and the reference values for the pPIs are defined, and the lower production control layer, which is responsible for maintaining the current pPIs values close to their reference values. During the research a production-process model and a simulator of the polymerisation plant were designed. Two types of production controllers were tested on this simulator: a look-up-table-based controller and a model predictive controller (MPC). The results obtained from several simulation runs show that the proposed pPIsbased production-control system is able to control the production process and has great potential for further research and implementation in practice. The pPIs used in the paper are rather basic. The main focus was on testing the suitability of the proposed control scheme. A more elaborate pPI design, e.g. based on IDPMS, QMPMS or ECOGRAI, might improve the control performance and could be the subject of further investigations.

The topics elaborated in this article are organised as follows: In Section 2 the closed-loop productionmanagement paradigm is explained. In Section 3 
a semi-batch production process is presented, including its process model and the proposed pPIs. Section 4 presents the implementation of closed-loop control on the production model and its simulation results. The conclusions follow in Section 5.

\section{Closed-loop production-management paradigm}

In the management system of a process-production enterprise, automated closed-loop control structures are massively used at the process level; however, they are less formal and seldom automated at the production level, and almost never automated at the business level. At the production-management level, the main mission of a production manager is to monitor the current performance of the technological process by observing the most important pPIs, e.g. the utilisation of production capacities, the quality of the raw materials and the product, the stocks, the available energy sources, etc. In the case when the pPIs deviate from expected values, production managers have to make on-the-spot adjustments to the direct inputs in the production process so as to achieve the desired global production goals. From this point of view they are performing the role of a hierarchically higher controller, while the task of the control systems on the lower shop-floor level is to execute process-control actions in accordance with the production manager's demands, all in order to achieve the desired behaviour of the whole production system. Thus, the optimisation of a production system can be achieved by properly defining the set-points' values for the most important production parameters - the pPIs. These values are adjusted in accordance with the current plans and other requests from the business management level, the current situation in the production process and the accepted production strategy (e.g. the production of products with excellent quality, the most cost-effective operation, etc).
The idea of hierarchical control levels is related to the so-called self-optimising control that was presented by Skogestad (2000, 2004). Generally speaking, for many systems (companies, chemical processes, biological systems, etc) we have available degrees of freedom (decisions), $u$, that we want to use in order to optimise the system operation. With the proper selection of the controlled variables, $c$, and the setpoints, $c_{s}$, for these variables it is possible to operate in a near-optimal regime just by preserving these variables at defined set-points. With this approach the complex optimisation problem can be translated to a simpler control problem. Figure 2 shows the described self-optimising control scheme.

While the closed-loop is a well-established paradigm in the control domain (Levine 1996), the complexity of the plant-wide control system and the problem of choosing proper manipulating and controlled variables from the number of available signals represent the main issue in control design. The selfoptimising concept in relation to the pPIs solves this problem in a way that fits in the classic productioncontrol structure

Figure 3 presents the generalised, hierarchical control-loop scheme for the whole production process based on the self-optimising control approach and pPIs. Plant-wide control structure consists of several layers operating on different timescales and levels of hierarchy. On the optimisation level, represented by the upper control loop, the production manager optimises the production process by selecting appropriate reference values for the pPIs in the control loop on the lower production-control level. Based on the definition of the pPIs, their values $(K)$ can be calculated online from measurable process data. The model describing the physical behaviour of the process projected on pPIs is derived from the archived process data $(y)$. If there were no changes in the process environment, there were constant measurable

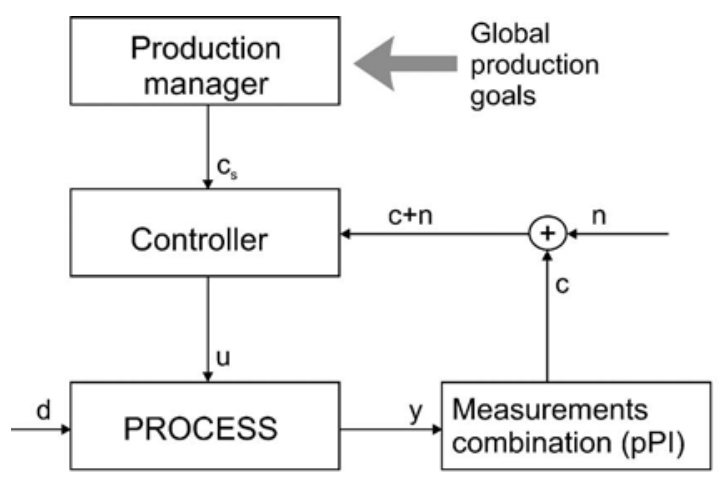

\author{
d - disturbance \\ $\mathrm{n}$ - implementation error \\ $\mathrm{u}$ - input (manipulative) variables \\ y - measured (process) variables \\ c - controlled variables \\ $\mathrm{c}_{\mathrm{s}}$ - reference value for controlled variable
}

Figure 2. Implementation of the optimal operation of a process with separate layers for optimisation and control (Skogestad, 2004). 


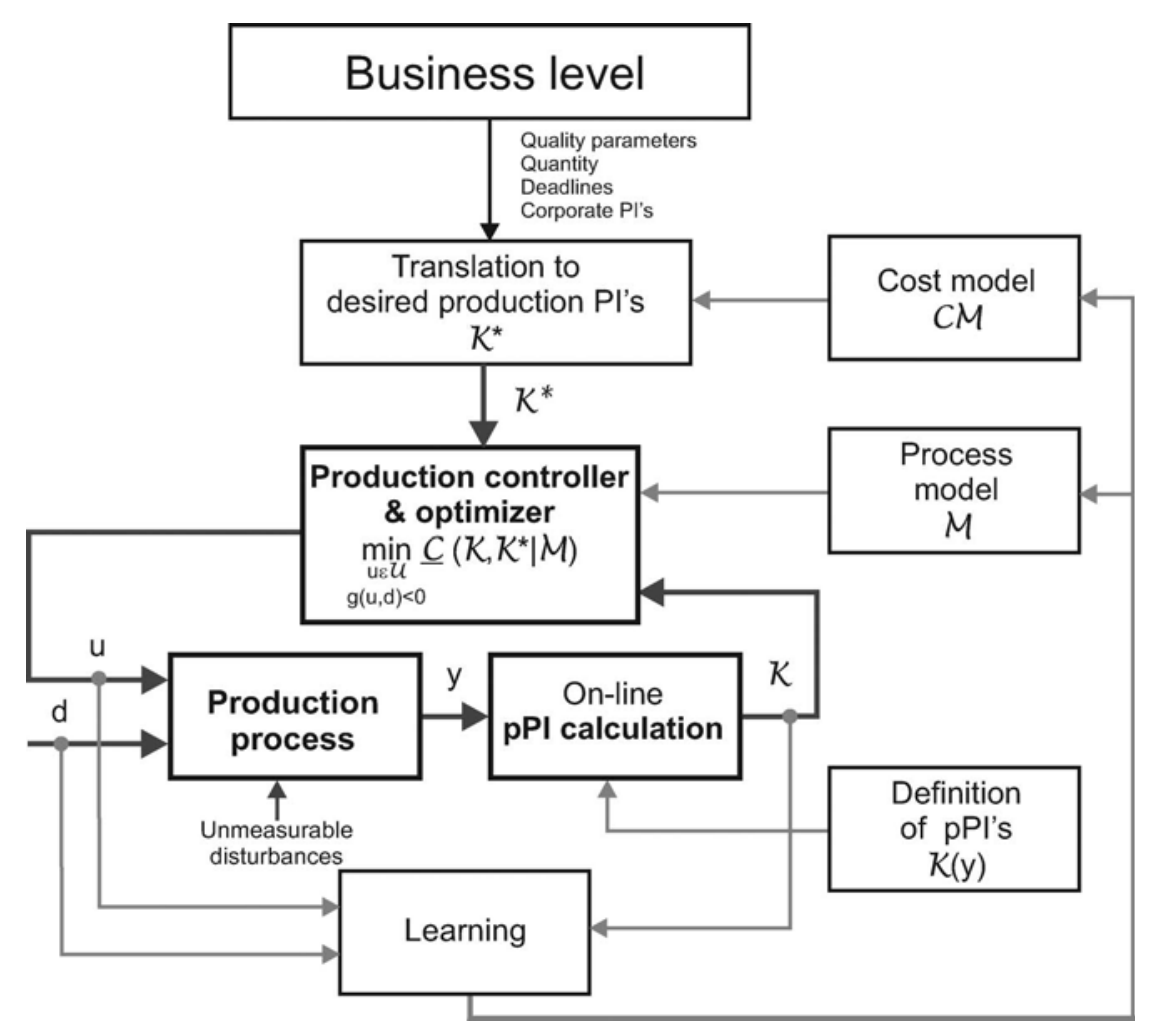

Figure 3. Generalised hierarchical scheme of a closed-loop production control.

influences, $d$, and there were no unmeasurable disturbances, then a suitably fixed setting, $u$, would solve the (optimal) control on the production level. As this is never true, an appropriate strategy to respond to the perturbations from the environment by readjusting the manipulative inputs $(u)$ is needed. Basically, this problem converts into the constrained-optimisation problem. The translation of the demands from the business level into the ideal pPIs $K^{*}$ is conditioned by the economic/cost model of the underlying process.

According to the proposed closed-loop control scheme, where the control problem is decomposed on two hierarchical levels, two different models of production usually need to be developed. On the optimisation level a production-costs model $(C M)$ has to be developed to support the production managers' decisions for the most suitable set-point values of the observed pPIs. Also, the design of the production controller (e.g. model-based control) on the lower control level usually needs a process model $(M)$.

\section{Case-study production process}

The presented case study addresses the closed-loop control of a production process in a polymerisation plant. The chosen batch-production process is a typical representative of process-oriented production. The installed DCS and SCADA systems do not handle the production process completely automatically, and not all the production-process variables are available online for use in a control system. For that reason we have decided to develop a procedural productionprocess model of the case-study production process. The next reason for this decision was to enable fast simulation runs of various regimes of the case-study production and to avoid interfering with the actual production process. The developed model of production was further used to design a production cost model as part of a plant-wide control structure and to evaluate the two feedback-based production-control approaches.

\subsection{Description of the polymer-emulsions production process}

The production process consists of three main reactors and two supplementary reactors, dosing vessels, storage tanks and equalisers that are used for the production of various polymer-emulsions. The technological process is defined by a recipe: a sequence of operations that must be performed for the production of a particular product. Various recipes performed simultaneously can share some common resources. To ensure good utilisation of the equipment and 
simultaneously satisfy safety requirements, technological and organisational constraints, proper scheduling of the production jobs must be defined.

The polymerisation process for the production of one batch of emulsion can be represented by the statetransition diagram that is depicted in Figure 4 and consists of three main stages: (i) the preparation of raw materials, (ii) the reaction process and (iii) the product analysis and reactor discharge. The optional stage of the product equalisation takes place in the equalisator.

The main characteristic of this batch-production process is the production of successive batches using a variety of equipment in which intermediate products appear during each batch stage and must be used in successive stages as soon as possible. In each step certain physical actions (heating, blending) or chemical reactions are involved. As already mentioned, the installed control equipment does not handle the production process completely automatically, which affects the quality of the product, the duration of a single batch and, consequently, the utilisation of the reactors and the production process itself. The increased production rate can cause an operator to become too busy and his/her ability to control the production efficiently can be reduced.

The utilisation of the whole production process depends on the execution of a list of production jobs (the batch-production process, cleaning the reactor, equalising a few batches of the same product, etc.), which in the production process is handled manually. The production of batches of equal products together in each reactor reduces the set-up times that appear in

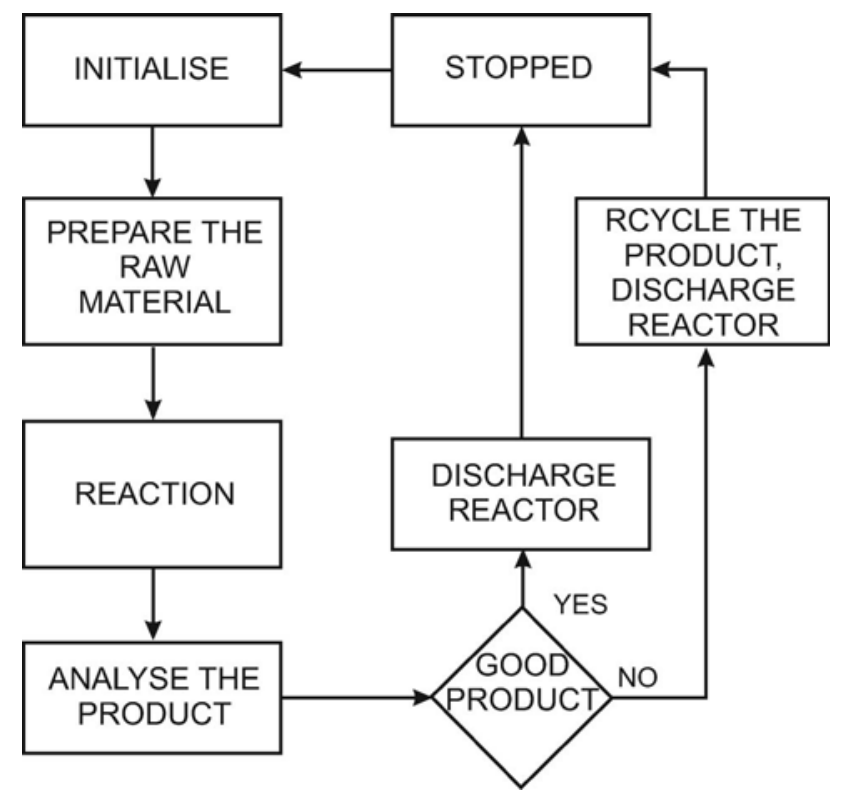

Figure 4. State-transition diagram of the polymerisation process. the case when the products from one reactor are mixed (additional equipment cleaning is needed, etc.). Speed of production and quality of raw materials have a large influence on the product quality, production costs and efficiency.

\subsection{Production process model}

The demands on the model of the case-study production process have many specifics that are not easy to implement in commercially available modelling and simulation tools. To avoid this trap, the model was designed in an academically well-established Matlab, Simulink and Stateflow simulation environment. The simulated data are stored in an MS Access Database and are available for online and offline processing.

The developed production process model of the polymerisation plant represents the production process and its attributes (utilisation of resources, production gain, product quality, production costs, etc) in the form needed for production management. This means that we have modelled physical realities of the process as well as production costs and quality aspects of the process.

The model is structured in six logical units that are interconnected as depicted in Figure 5:

- Basic equipment models, created in Simulink,

- Procedural control of the equipment, created in the Stateflow toolbox,

- Dedicated Matlab functions,

- Graphical user interface (GUI),

- pPIs model,

- External MS Access database for data storage.

The equipment models are simple Simulink models that incorporate input/output (I/O) control signals. The Simulink models of the chemical reactors do not

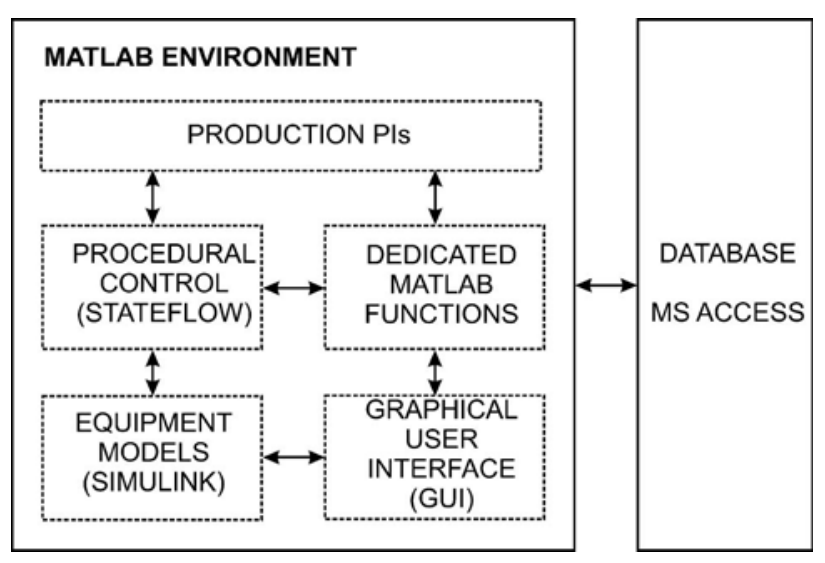

Figure 5. The structure of the production process model. 
include the exact mathematical formulation of the chemical reactions involved in the polymerisation process (they are too complex and, at this level of interest, they are not necessary), but they do include the equations of temperature, flow and level dynamics. The Stateflow chart uses dedicated Matlab functions to evaluate other properties (e.g. the product quality) of the chemical reactions. These functions were designed and calibrated on the basis of statistical analyses of the production data and on knowledge about the production process obtained by interviewing production operators and technologists. For example, the quality of the product is estimated from the normalised factors representing different quality aspects of production that are contained in one normalised factor for each finished batch, as represented in Equation (1).

$$
Q_{P}=q_{R M} \cdot q_{S} \cdot q_{R P} \cdot q_{P S} \cdot q_{T C}
$$

subject to:

$Q_{P}-$ normalised quality factor for a batch of a single product

$q_{R M}$ - normaised factor, representing the quality of the raw materials

$q_{S}$ - normalised factor, representing the influence of the stops in production

$q_{R P}-$ normalised factor, representing the influence of the reactor' purity

$q_{P S}-$ normalised factor, representing the influence of the production speed

$q_{T C}-$ normalised factor, representing the quality of the temperature control

The normalised factor for the influence of the reactor's purity is estimated using Equation (2)

$$
q_{R P}=(1+0.02)^{-n}
$$

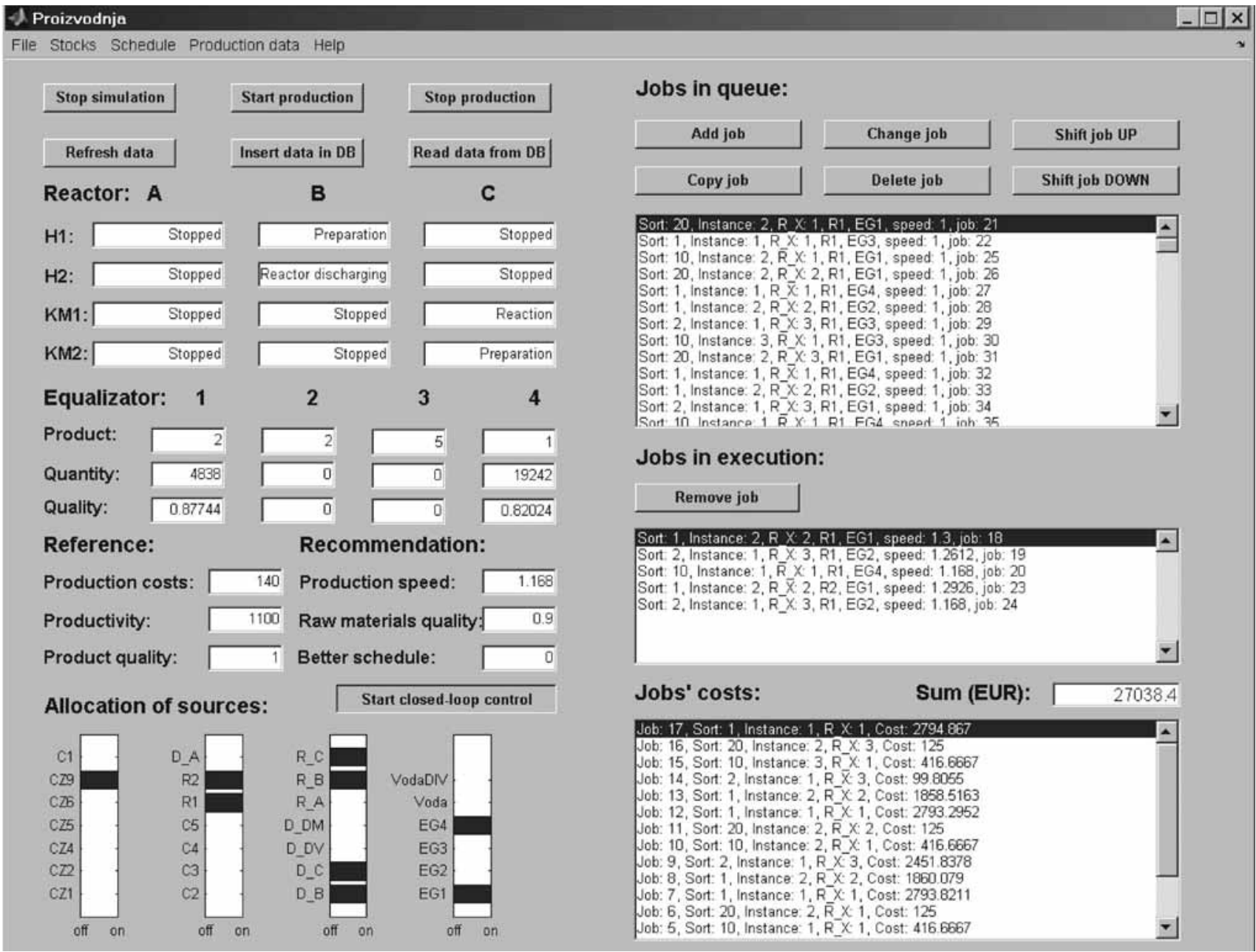

Figure 6. GUI for the polymerisation-production process simulator. 
subject to:

$q_{R P}$ - the influence of the reactor's purity

$n$ - the number of batches since the reactor has been cleaned.

Production-process control logic was implemented using Stateflow charts, and with them the $\mathrm{I} / \mathrm{O}$ control signals are simulated.

The main purpose of designing the productionprocess model was the capability of simulating the execution of scheduled jobs in production and of investigating the plant-wide control algorithms. The production jobs are scheduled according to the demands from the business management level (due times, desired product cost and quality, etc) and other production constraints (production rate, availability of resources, etc). This production job schedule represents an input variable in the production-process model. The other two input variables that define the production process are the Production speed and the Raw materials' quality, and these are described in more detail in Section 4.1.

The graphical user interface (GUI) (Figure 6) enables the user to simulate the production process; the user can manipulate online the job schedule, the production speed and the raw materials' quality. On the other hand, the GUI presents the current state of the equipment (reactors, equalisator, etc) and enables statistical analyses and a visual representation of the historical production data as well as the pPIs.

\section{3. pPIs for the polymerisation production plant}

For the case-study production process presented in this article the Productivity, Product Quality and Production Costs pPIs were selected to obtain information about the current status of the production process. None of these pPIs is directly measurable, but an estimation of their current values can be made using the combination of the measurable output productionprocess variables.

The procedure for the pPIs calculation has two characteristic parameters:

- The pPIs' calculation frequency $f_{P I}$ : this defines the time frames in which the pPIs are evaluated.

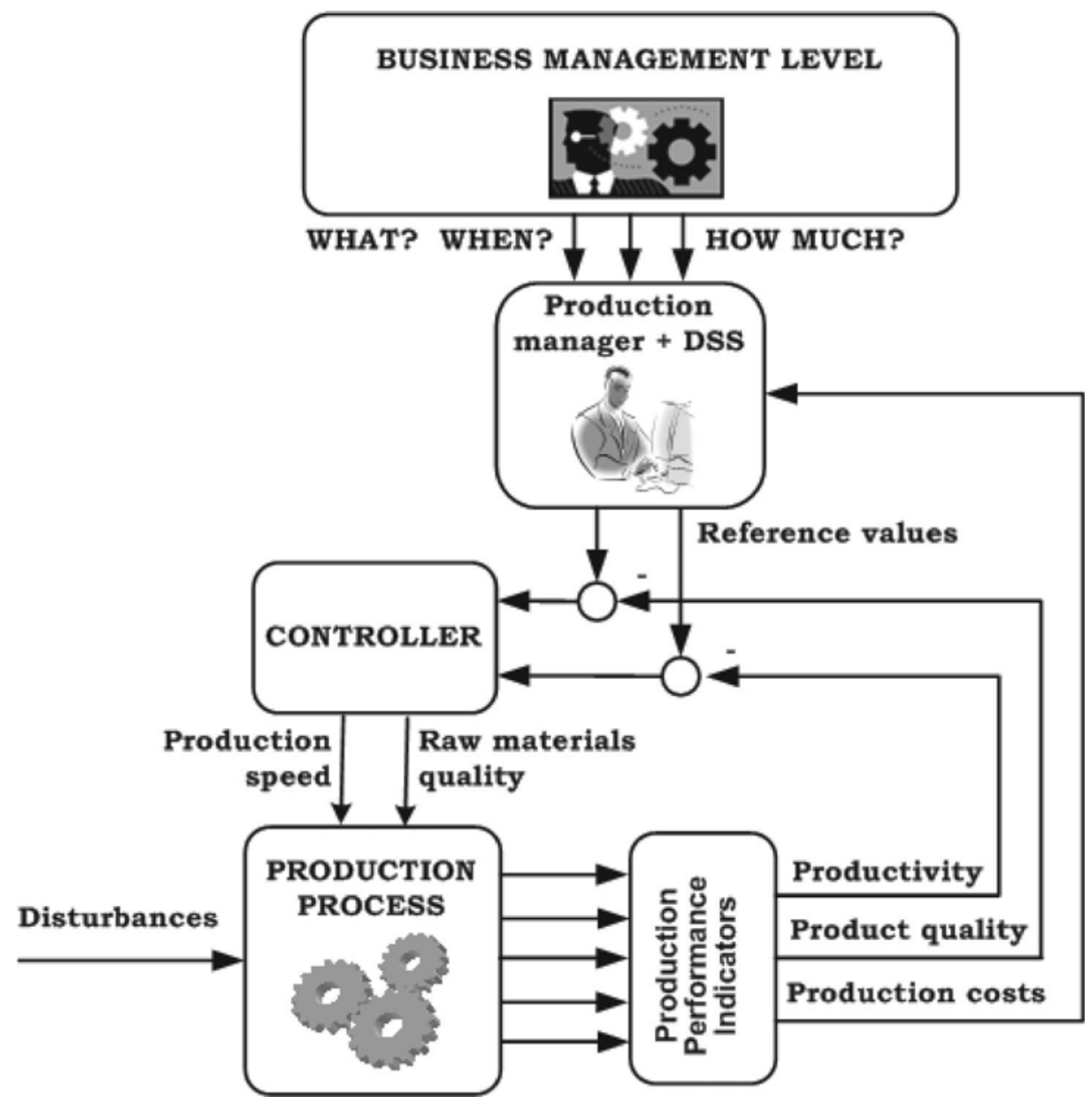

Figure 7. Hierarchical closed-loop control scheme for the polymerisation. 
- The pPIs' calculation window $T_{P I}$ : this time window defines which production history data are used for the evaluation of the pPIs.

These two parameters have a special effect on the evaluation of the pPIs. For example, if the calculation window $T_{P I}$ is increased, the dynamics of the calculated pPIs are decreased and vice versa. In our case the simulation runs were performed with a calculation frequency of one evaluation per 5 hours, and with the size of the calculation window being 100 hours. These time constants were chosen empirically, on the recommendations of the factory technologists and on the basis of simulation results.

\subsubsection{Productivity}

For the described production process, Productivity $P$ $(\mathrm{kg} / \mathrm{h})$ is defined as the amount of all products that were produced in a certain production period, and this amount is defined with Equation (3)

$$
P=\frac{\sum_{i=1}^{n} k_{i} \cdot M_{i}}{T_{P I}},
$$

where $k_{i}$ represents the correction factor; $M_{i}$ is the batch quantity $(\mathrm{kg}) ; T_{P I}$ is the calculation window (h); and $n$ is the number of observed batches. We take into consideration all the batches that were completely or partly produced in the defined calculation window and calculate the average amount of products that was produced in an hour. The average batch production time (cca. $15 \mathrm{~h}$ ) is significant in comparison with the calculation window $\left(T_{P I}=100 \mathrm{~h}\right)$. In the case that the batch is not completely produced in the calculation window because the production of the batch started before the calculation window is started or because the batch is still in progress, it is useful to introduce the correction factor $k$, which defines the portion of each batch-production time that fits into the observed calculation window. When the Productivity indicator is evaluated, such batches are only considered with the corrected quantity.

\subsubsection{Product quality}

Another important indicator of production efficiency is the Product quality $Q_{P}$ (no unit), which is calculated as the mean value of the normalised quality factors of the batches that were completed in the observed

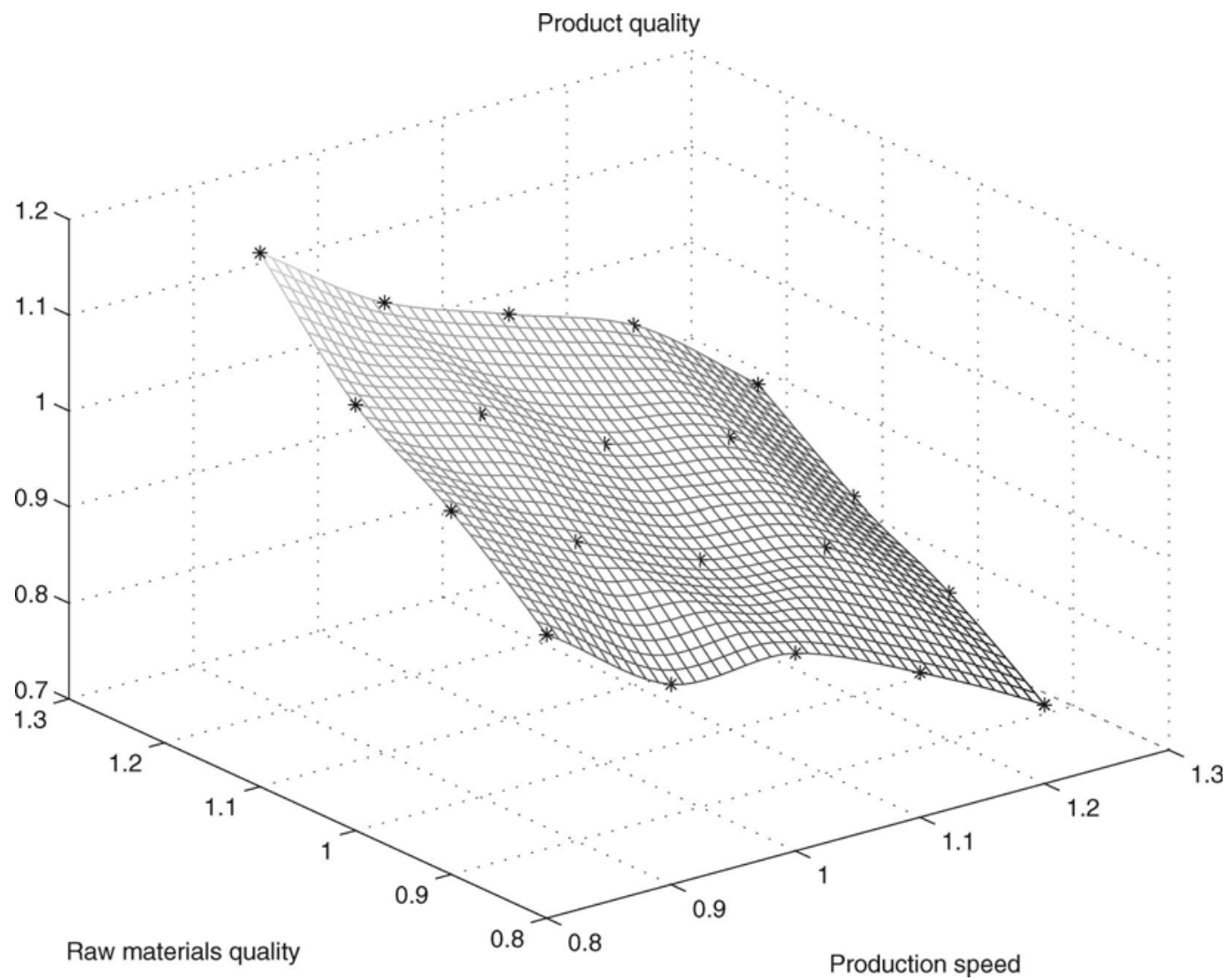

Figure 8. Product quality PI in relation to Raw materials' quality and Production speed. 
calculation window $T_{P I}$. Because the quality factors are normalised, this pPI has no unit. The mean product quality is calculated with Equation (4)

$$
Q_{P}=\frac{\sum_{i=1}^{n} Q_{i}}{n}
$$

where $Q_{i}$ (no unit) is the normalised quality of a single batch and $n$ is the number of observed batches that are partly or completely produced in calculation window.

\subsubsection{Production costs}

The production costs $(\mathrm{Eur} / \mathrm{kg})$ consist of variable costs (raw-materials costs, energy costs, and other operating costs) and fixed costs (amortisation of the equipment, labour costs, etc). The mean production costs (per kilogram of final product), $C$, are calculated as the sum of all the costs related to production in the observed production period divided by the total amount of products produced in that production period (Equation (5))

$$
C=\frac{\sum_{i=1}^{n} k_{i} \cdot C_{i}+T_{P I} \cdot C_{f}}{\sum_{j=1}^{m} k_{j} \cdot M_{j}}
$$

where $k_{i}$ is the correction factor for the job costs; $C_{i}$ is the job cost (Eur); $T_{P I}$ is the calculation window (h); $C_{f}$ is the rate of fixed costs per production hour (Eur/h); $n$ is the number of the observed jobs; $M_{j}$ is the batch quantity $(\mathrm{kg}) ; k_{j}$ is a correction factor for the batch quantity; and $m$ is the number of observed batches. Correction factors are evaluated in the same manner as in Section 3.3.1. The estimation for production costs is helpful for the production costs optimisation.

\section{Closed-loop control of the polymerisation plant}

To control the modelled process a control system was designed, with the control being performed on different levels of decisions. The minimisation of production costs is the highest priority, and the majority of control actions are made to fulfil this demand. The demands from the business-management level are expressed in the production schedule and the desired production costs. The production jobs schedule represents an input variable that has a significant impact on the pPIs, but it is performed manually once or twice a week, and for that reason there is no need to use it in direct closedloop control.

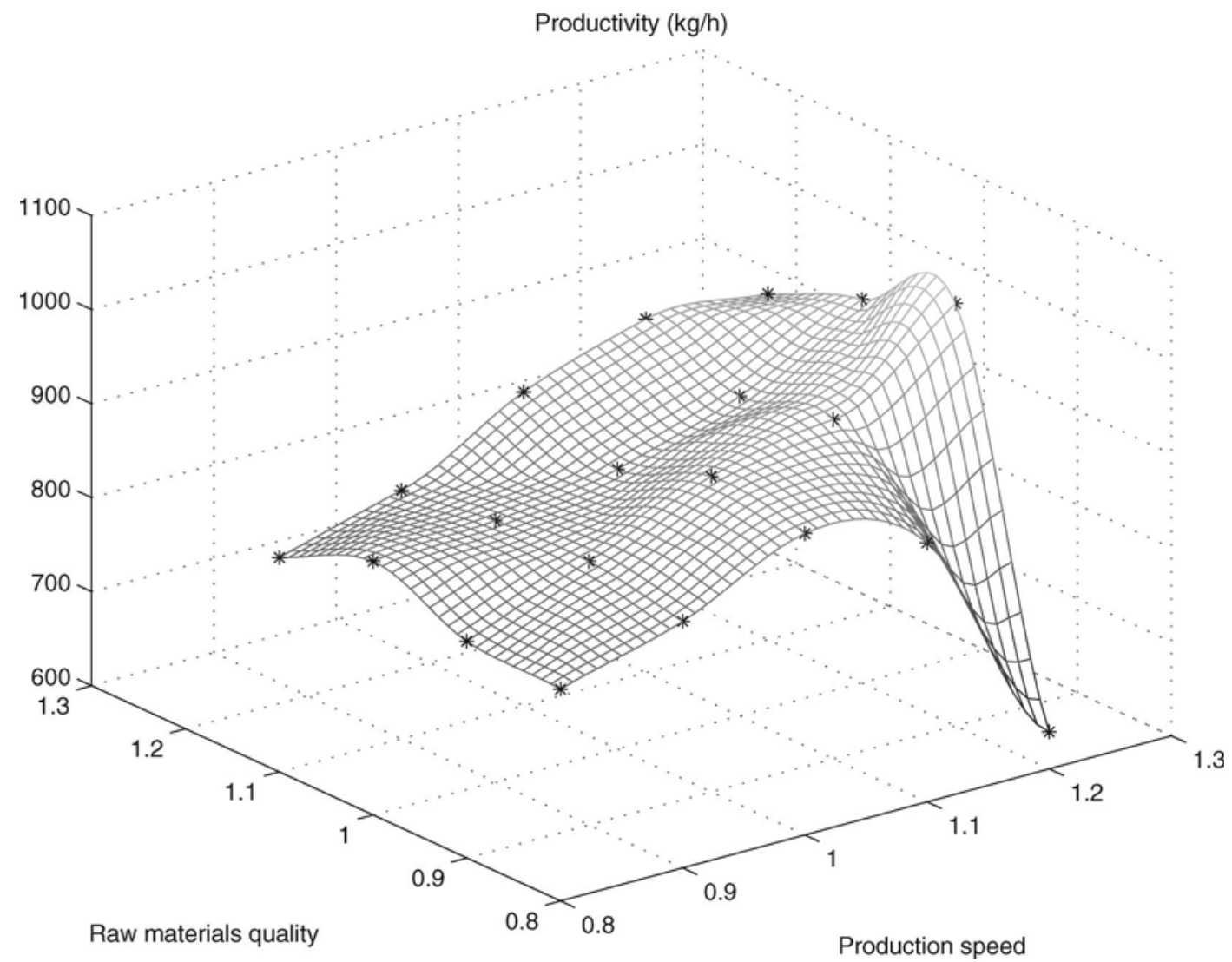

Figure 9. Productivity PI in relation to Raw materials' quality and Production speed. 


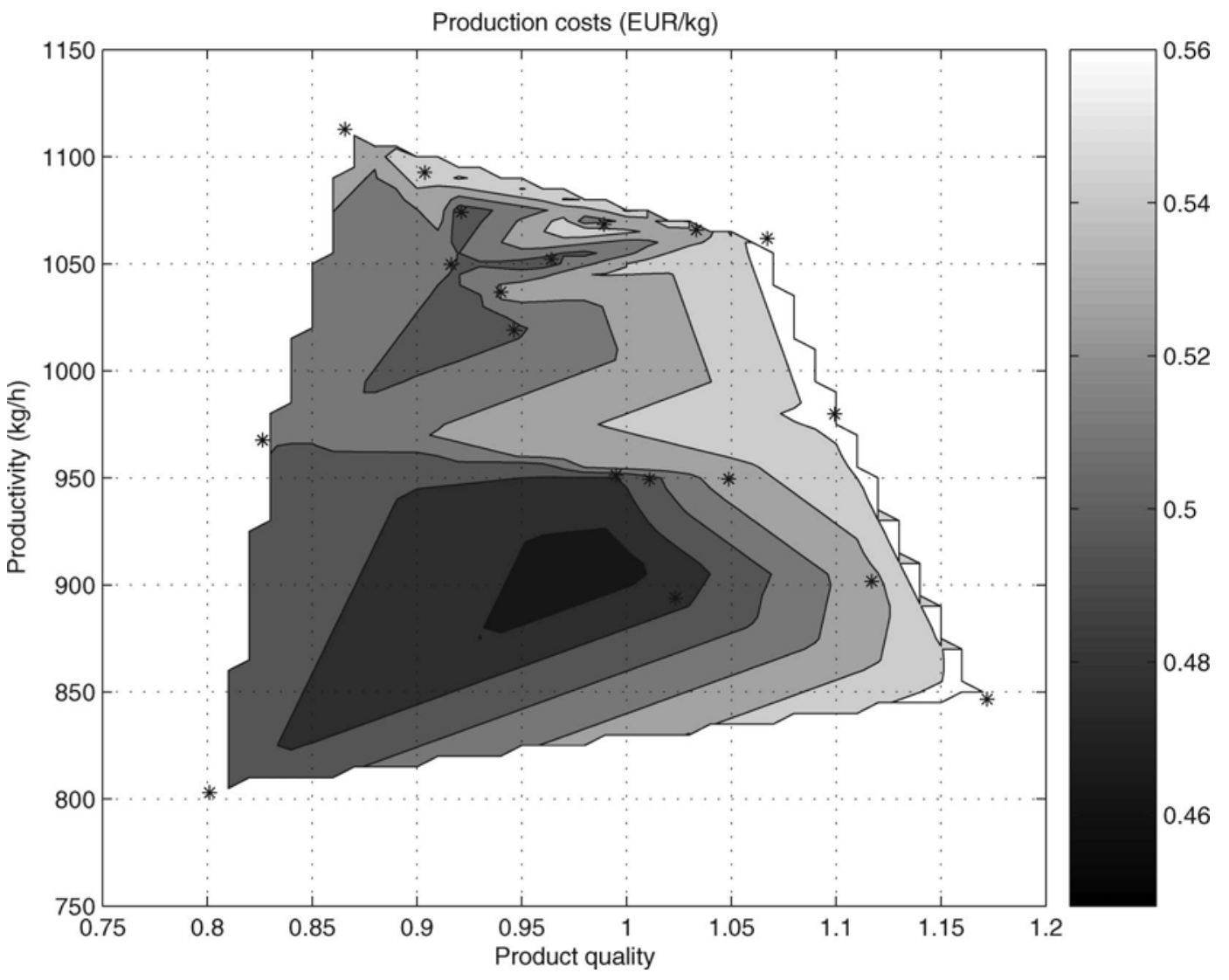

Figure 10. Production costs in relation to Productivity and Product quality pPIs for unified production.

Figure 7 represents an adapted version of the basic hierarchical control structure from Figure 3. On the process-optimisation level the cost optimisation is performed by the production manager, who is using the current value of the Production costs pPI, the job schedule and a production cost model to define the optimal set points for the Product quality and Productivity pPIs. The production costs' model is constantly updated with current data and its simulation runs can provide vital information for defining the appropriate reference values for the chosen pPIs. Thus, a production costs' model acts as a kind of decision support system (DSS) for the definition of references for the pPIs. Once the pPIs' reference values are defined they are maintained by the production controller, which controls the execution of the production jobs' schedule by adjusting the available degrees of freedom for the chosen production processes, which are Production speed and Raw materials' quality.

\subsection{Production cost optimisation}

To be able to define a production costs' model, a sensitivity analysis of the pPIs has to be made.
Figures 8 and 9 describe the dependence of the Product quality and Productivity pPIs on the process input variables (Production speed and Raw materials' quality) for a fixed batch schedule. The pPIs were evaluated at 20 working points and connected together by extrapolation. The Production speed defines the production rate, and is normalised. During normal production there is enough time for all the production cycles to be finished in the required time. An increased production speed represents an increased production rate, where some production phases (e.g. vacuuming) have to be shortened, and this normally decreases the product quality and increases productivity. When the production speed is increased, the productivity is increased, but on the other hand, the operator's ability to control the reactor temperature is decreased, which normally decreases the product quality and vice versa. The efficiency of the production process is also affected by disturbances; the most significant are equipment failures, delays in the production process, variations in the quality of the raw materials, new high-priority orders, a shortage of raw materials on the market, illness, etc. Some of these disturbances are included in the model as random events. The Raw materials' quality is also presented as a normalised entity, where the value 1 


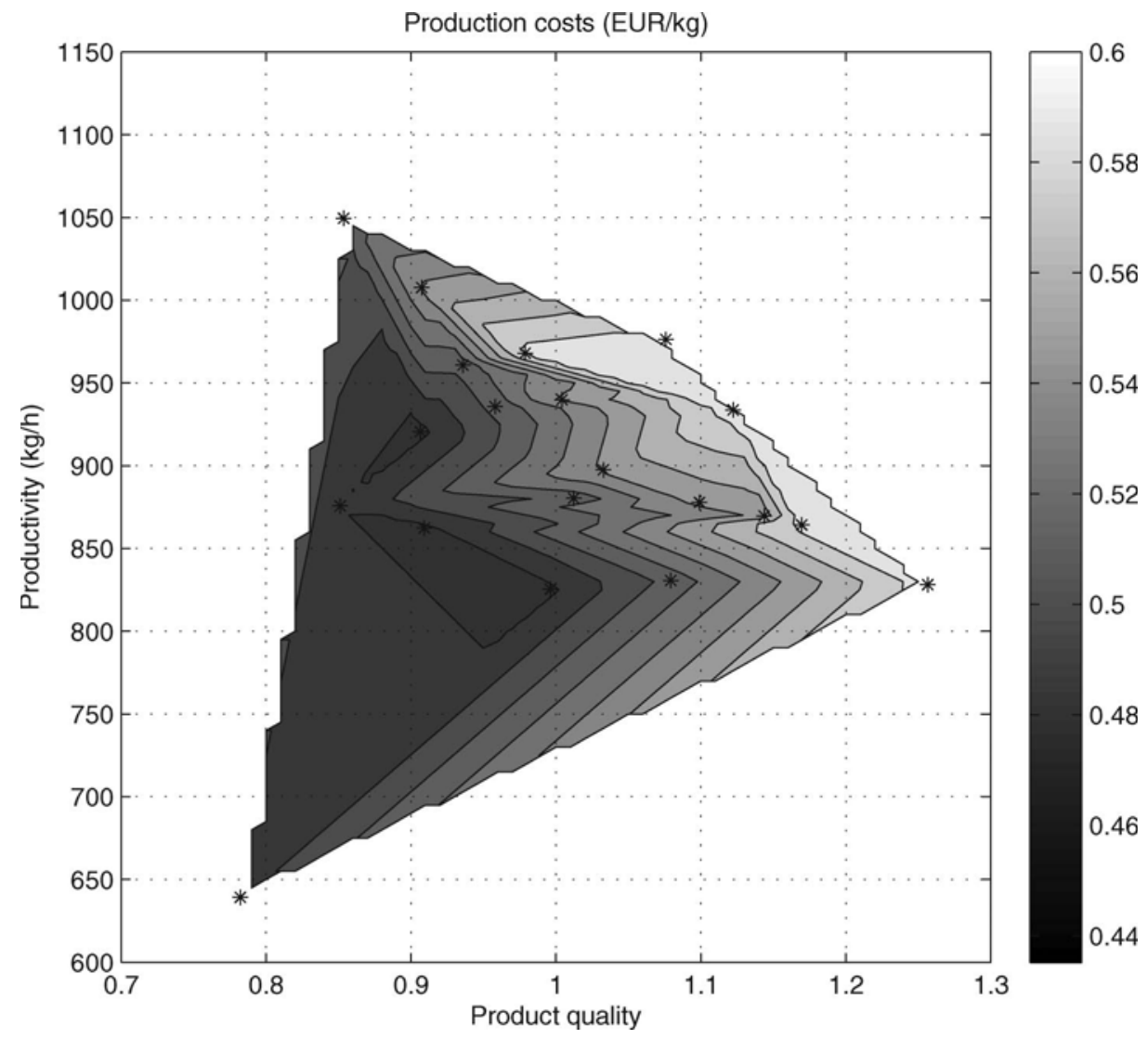

Figure 11. Production costs in relation to Productivity and Product quality pPIs for mixed production.

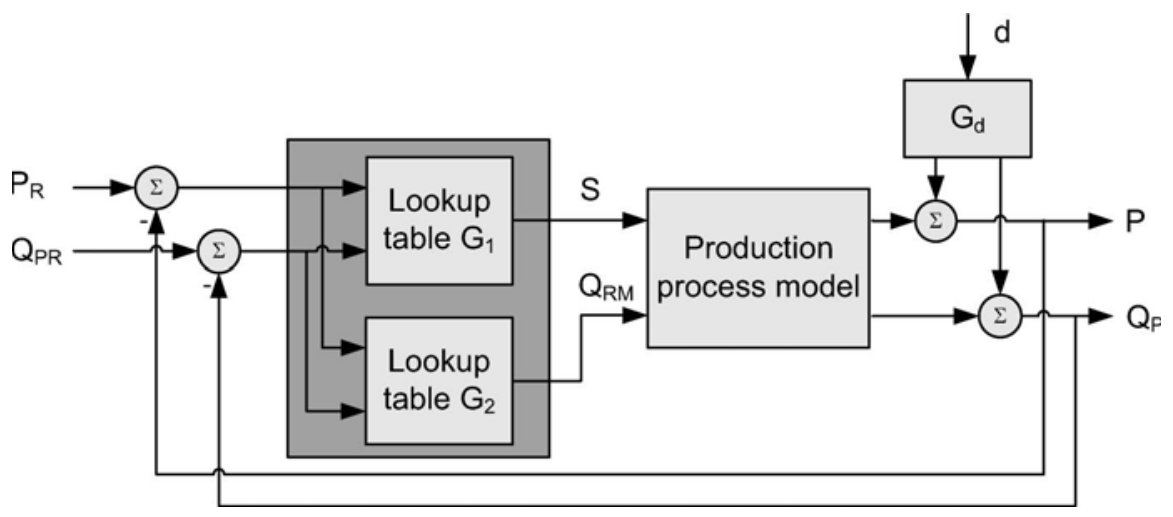

Figure 12. Internal closed-loop control scheme based on look-up tables.

represents a quality of raw materials that is most suitable in relation to cost/performance aspects. Good Raw materials' quality (1.2) enables the production of products with sufficient quality in worse production conditions, which are normally represented during an increased production speed. Extreme working conditions, like high Production speed (1.2) and low Raw materials' quality (0.8), can result in batches of insufficient quality, which then have to be recycled. This introduces additional analyses and work that are connected with delays in the production process, increased production costs and, consequently, lower Productivity, as can be seen in Figure 9.

Figures 10 and 11 show the relation between Production costs, Product quality and Productivity pPIs, i.e. the dependence of the Production costs 
regarding Productivity and Product quality. Figure 10 shows the results for unified production (a production where a series of batches of the same or similar final products are performed on each reactor - production for stock) and Figure 11 shows the results for mixed production (a production where products are changing from batch to batch on each reactor - production on demand). The production of batches of equal products together in each reactor reduces the set-up times that appear in the case when the products from one reactor are mixed (additional equipment cleaning is needed, etc). Both figures exhibit a noticeable global minimum where the production costs are minimal. In the unified production the Productivity pPI value ranges from 800 to 1100 , whereas in the mixed production it ranges from 650 to $1050 \mathrm{~kg} / \mathrm{h}$. The region with low Product quality and Productivity is not well defined because it is connected with the frequent production of bad batches and represents a working region that has to be avoided during normal production.

Performed PI sensitivity analysis support the idea of closed-loop control based on pPIs. These dependences can be further used to suggest production manager defining exact reference values for the Productivity and Product quality indicators. This is done by proper PI dependence that is relevant for the actual production schedule, and this activity is represented by the upper control loop in Figure 7.

\subsection{Design of the production controller}

As mentioned previously, optimal operating conditions can be ensured if selected pPIs (Productivity and Product quality) are being controlled at a predefined referenced value. The production controller performs the monitoring and controlling of these two pPIs to the reference values, defined by the optimisation level.

The production controller is placed in the lower hierarchical control loop in Figure 7. To design a controller a model of the production process is needed. The part that has to be controlled is a multivariable system that can be linearised for a commonly used working area. It has two input variables (Production speed and Raw materials' quality) and two output

Batch schedule on reactors $\mathrm{R}-\mathrm{A}, \mathrm{R}-\mathrm{B}$ and $\mathrm{R}-\mathrm{C}$
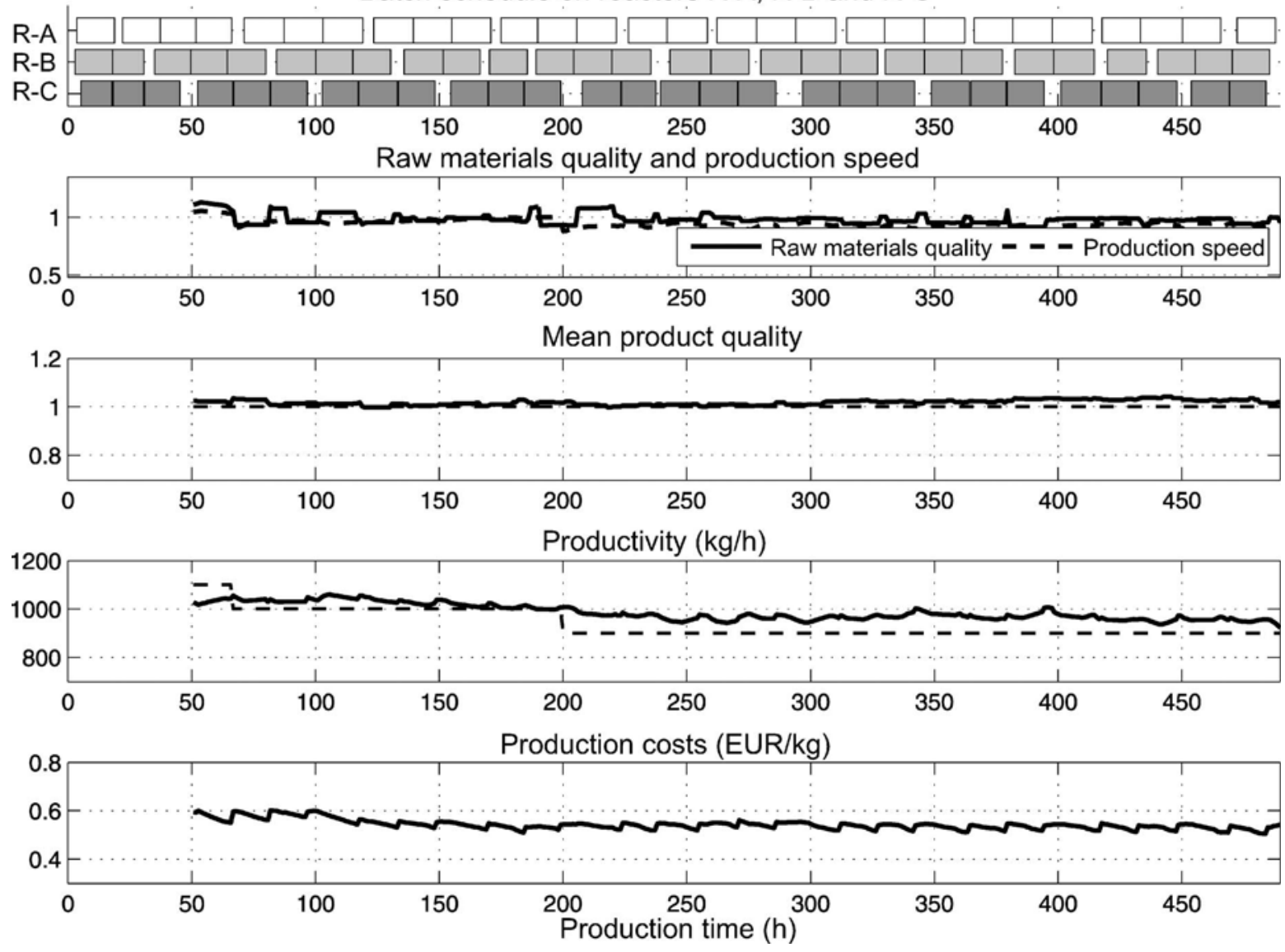

Figure 13. Production PIs' control using a look-up-table-based controller. 
variables (Productivity and Product quality). In the remaining part of the paper, two controllers will be presented:

- A controller based on look-up tables,

- A multivariable predictive controller (MPC).

A controller based on look-up tables simulates the production managers' control actions in one working region of the production process. The controller consists of two look-up tables, the first manipulates Production speed $S$, and the second one manipulates Raw materials' quality $Q_{R M}$ according to the control error (Figure 12). $P$ represents the Productivity $\mathrm{pPI}$ and $Q_{P}$ represents the Product quality pPI. The control scheme also includes control disturbances that are always present in real systems. The look-up tables $G_{l}$ and $G_{2}$ were defined on the basis of a sensitivity analysis of the production-process model and on the expertise of experienced technological staff. $P_{R}$ and $Q_{P R}$ are reference values for controlled pPIs. The first diagram in Figure 13 shows the batch schedule for the production of Product 1 in Reactor R-A, Product 2 in Reactor R-B and Product 3 in Reactor R-C. The spaces between batches represent reactor cleaning procedures and bottlenecks. The second diagram shows the trace of the manipulated variables during the experiment and the remaining three diagrams show the traces of the controlled pPIs.

The main drawback of the presented controller is the control error in steady state, which can be observed in Figure 13 when the set-point for the Productivity pPI is different from $1000 \mathrm{~kg} / \mathrm{h}$. This is a consequence of the property of the presented controller that is in fact a $\mathrm{P}$-controller with variable gain.

In the next step, the model-based control strategy was developed. This model-based strategy has to operate in an online regime and has to account for any natural physical limitations. The controller has to recognise the interaction between multiple inputs. Model predictive control (MPC) is well suited to solving this constraint problem (Morari and Lee 1999, Qin and Badgwell 2003), and multivariable process control using MPC has been thoroughly

Batch schedule on reactors R-A, R-B and R-C

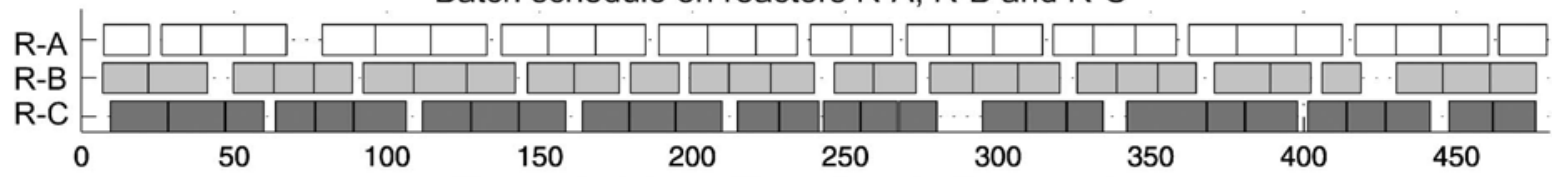

Raw materials quality and production speed
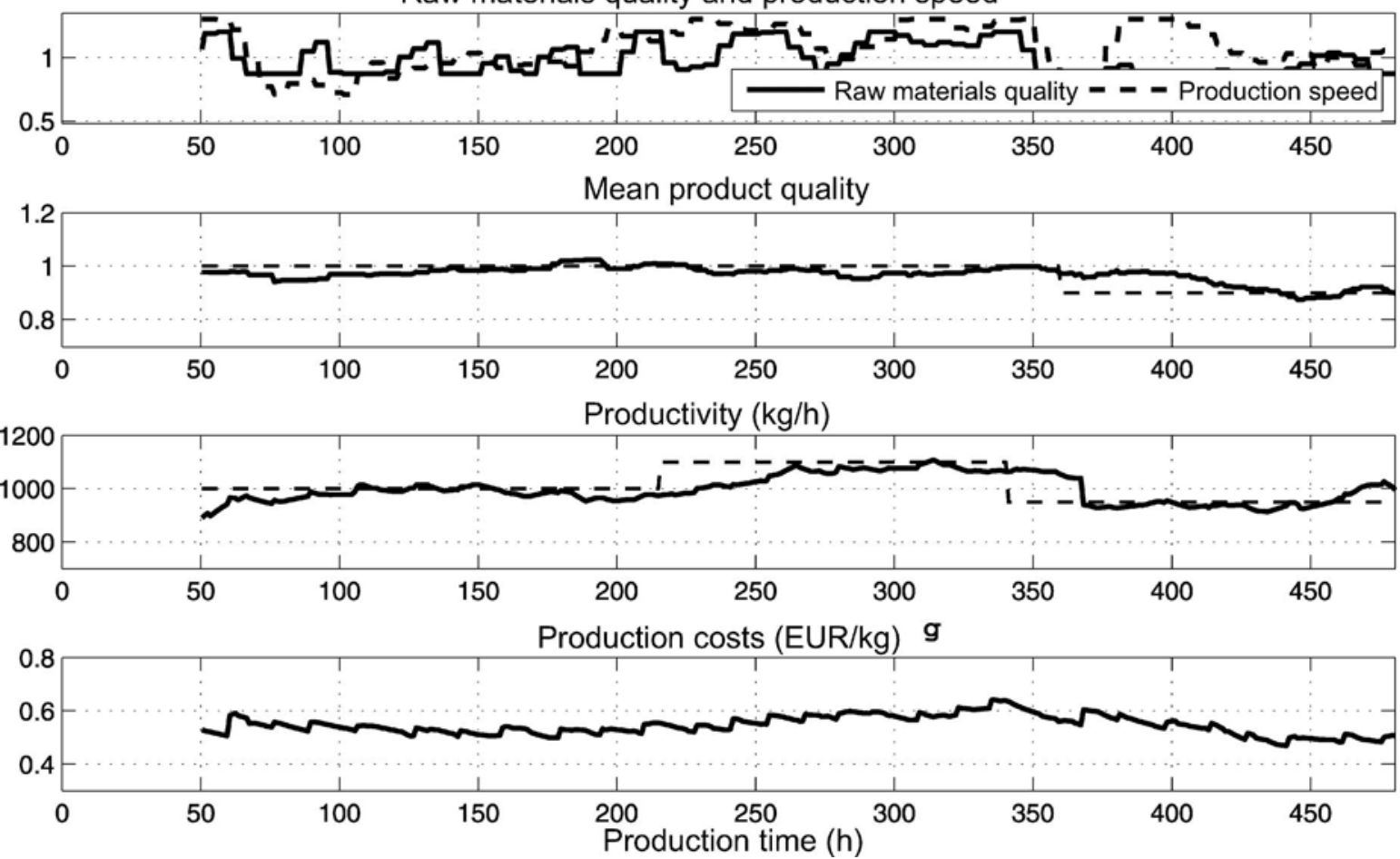

Figure 14. Batch schedule, input and output variables for one simulation run for normal production. 
studied (Maciejowski 1989, Škrjanc et al. 2004). MPC, or receding horizon control, refers to a class of control algorithms in which a dynamic process model is used to predict and optimise process performance.

The designed production-process model, presented in Section 3, is not suitable for the MPC construction, and for that reason a simplified, dynamic, linear process model was obtained by using the identification process over the earlier developed production-process model. In the identification process, input-output data that were obtained from several simulation runs were used. During the identification process it was assumed that the process is linear. In such a situation an approach where one input is changing while another one is fixed can be used. In the first experiment the Raw materials' quality was fixed and the influence of Production speed on the outputs of the system (Productivity and Product quality) was studied. The same experiment was repeated, but in this case the Production speed was fixed and the influence of Raw materials' quality was studied. The model parameter estimation was made using the identification method in which the least-square criterion was minimised (Levine 1996). The input-output dependencies are therefore given with first-order models (Equation (6)), where the sampling time $\mathrm{T}_{\mathrm{S}}$ was 5 hours.

$$
G=\left[\begin{array}{cc}
\frac{31.84}{z-0.938} & \frac{-4.43}{z-0.834} \\
\frac{-0.04}{z-0.932} & \frac{0.052}{z-0.94}
\end{array}\right], T_{S}=5 h
$$

This multivariable model $G$ was used for the MPC controller design, where the MPC Toolbox from the Matlab environment (Bemporad et al. 2006) was used.

The main challenge was the tuning of MPC controller's cost function parameters. The MPC toolbox supports the prioritisations of the outputs. In this way, the controller can provide accurate set-point tracking for the most important output, sacrificing others when necessary, e.g. when it encounters constraints. In our case the controller has to consider the input and output constraints as defined by Equation (7). In order to eliminate the production of
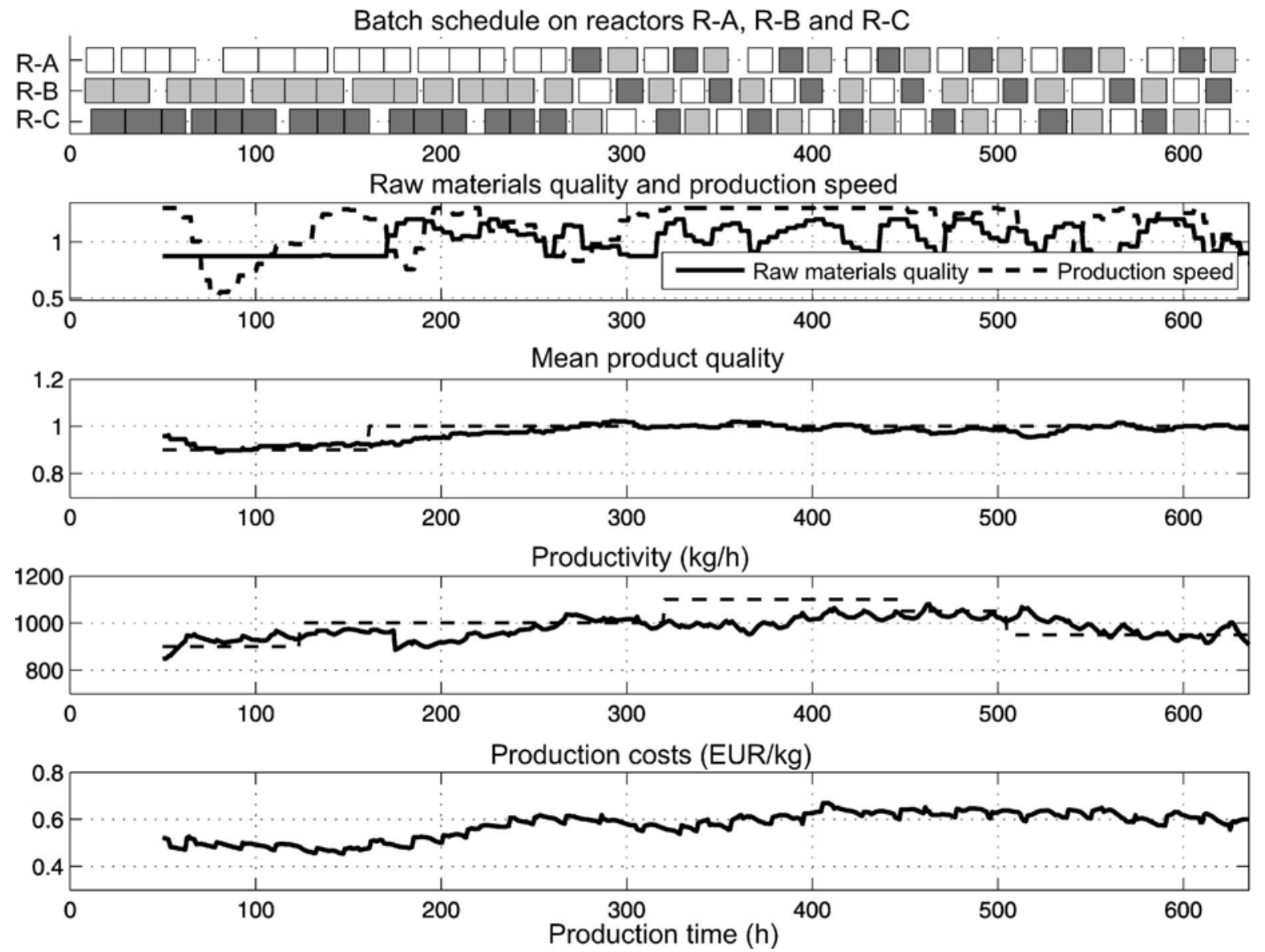

Figure 15. Batch schedule, input and output variables for the case when the production schedule is changed during the simulation run. 
batches of insufficient quality we had to constrain the lower limits of the Raw materials quality and Product quality. Production speed and Product quality represent physical constraints of the production process.

$$
\begin{aligned}
0.5 \leq S & \leq 1.3 \\
0.85 \leq Q_{R M} & \leq 1.2 \\
\text { and } 700 & \leq P \leq 1300 \\
0.87 & \leq Q_{P} \leq 1.3
\end{aligned}
$$

Different weights were used to prioritise the input and output variables. To solve the optimisation problem, a prediction horizon of $100 \mathrm{~h}$ and a control horizon of $40 \mathrm{~h}$ were used. The MPC toolbox uses the Quadratic Programming solver to solve the optimisation problem, where the bounds of the constraints are finite (Bemporad et al. 2006).

Closed-loop control was tested in several simulation runs. Figure 14 presents the results of an experiment where the set-point for Productivity was changed two times and the set-point for Product quality was changed just once. In the experiment a normal batch schedule for the production of three products, each of them produced in one reactor, was used. MPC managed to achieve the prescribed setpoints for the controlled pPIs (Productivity and Product quality). With the increasing set-point for the Productivity pPI the Production costs pPI is also increasing, and with the decreasing set-point for the Product quality pPI the production costs decrease. The Production costs pPI is not as smooth as the other two pPIs, which reflects the influence of the stops in production on the production costs. With an increased time horizon for the pPI evaluation such leaps in the pPI values are reduced, but also the pPI's dynamic is reduced, and consequently the performance of the MPC controller is also reduced. From the pPI responses on changed set-points for Product quality and Productivity pPIs the time constant of such a pPI model can be estimated at around $50 \mathrm{~h}$.

Figure 15 presents the situation when the production schedule is changed during the simulation. In the middle of the experiment the Productivity set-point is very high and an extremely mixed production is applied to the production process. Even in the case when the Production speed is at a maximum for almost all the time the Productivity pPI cannot reach the prescribed set-point. A closer look at Figure 11 reveals that the set-point for the Productivity $\mathrm{pPI}$ is set far outside the manageable working region. The MPC controller managed to reach the set-points for the controlled pPIs in the remaining part of the experiment. The presented results show that the designed
MPC controller is robust enough to control the production of different types of batch schedules.

\section{Conclusions}

Plant-wide control systems should ensure that the production process is constantly working in near optimality. This article uses an already-established approach to measuring and presenting the achieved production objectives in the form of $\mathrm{pPIs}$ and proposes the incorporation of pPIs into closed-loop productioncontrol systems.

The proposed production control system consists of hierarchically organised optimisation and control parts. In this way the production control concept and the role of a production manager are slightly changed; instead of monitoring and controlling several tens and hundreds of process variables at a low production level, a production manager monitors and controls only a few major production PIs with the aim of achieving the most important implicit production objectives, e.g. predefined product quality, high productivity and minimal production costs. The proposed idea was tested on a procedural model of a polymerisation production plant. The production manager handles the upper optimisation control layer where the set-point values for the Productivity and Product quality PIs are defined by using the production costs model. The pPIs are controlled to these set-points by the control-loop of the production controller (the lower layer of the production-control system), where two types of control strategies were tested: a controller based on look-up tables and a model-based controller (MPC). The utilisation of the MPC controller in the closed-loop control of the production process model returned better results. The testing of the presented production-control system was based on several simulation runs of the developed polymerisation production process model. The next step is the implementation of the developed production-control system in a real production plant, where first the availability of all the production data needed for an online calculation of the chosen pPIs has to be ensured. For this reason the existing DSC and SCADA systems should be upgraded to provide the additional production-process data.

\section{References}

Anthony, R., 1965. Planning and control systems: A framework for analysis. Boston, USA: Division of Research, Graduate School of Business Administration, Harvard University.

Bemporad, A., Morari, M., and Ricker, L., 2006. Model predictive control toolbox for use with MATLAB. Natwick: The Mathworks. 
Bourne, M.C.S., Mills, J.F., Wilcox, M., Neely, A.D., and Platts, K.W., 2000. Designing, implementing and updating performance measurement systems. International Journal of Operations and Production Management, 20 (7), 754-771.

Dangelmaier, W., Fischer, M., Gausemeier, J., Grafe, M. Matysczok, C., and Mueck, B., 2005. Virtual and augmented reality support for discrete manufacturing system simulation. Computers in Industry, 56, 371-383.

Fortuin, L., 1988. Performance indicators - Why, where and how. European Journal of Operational Research, 34, 1-9.

Folan, P. and Brown, J., 2005. A review of performance measurement: towards performance management. Computers in Industry, 56, 663-680.

Forza, C. and Salvador, F., 2001. Information flows for highperformance manufacturing. International Journal of Production Economics, 70, 21-36.

Ghalayini, A.M., Noble, J.S., and Crowe, T.J., 1996. An integrated dynamic performance measurement system for improving manufacturing competitiveness. International Journal of Production Economics, 48, 207-225.

Hales, H.L., 1989. CIMPLAN The systematic approach to factory automation. Arliington, VA: Cutter Information Corporation.

Holt, K., 1999. Management and organization through 100 years. Technovation, 19, 135-140.

Jovan, V., Černetič, J., and Dolanc, G., 1998. Integration of business and production levels in process Industries. In: INCOM'98 - Advances in industrial engineering: preprints of the 9th IFAC Symposium on Information Control in Manufacturing, 3, 275-280.

Kaplan, R.S. and Norton, D.P., 1992. The balanced scorecard - Measures that drive performance. Harvard Business Review, 71-79.

Lee, C.L. and Lai, S.Q., 1997. Performance measurement systems for knowledge management in high technology industries: a balanced scorecard framework. International Journal of technology Management, 39 (1/2), 158-176.

Levine, S.W., 1996. The Control Handbook. New York: CRC Press.
Lohman, C., Fortuin, L., and Wouters, M., 2004. Designing a performance measurement system: A case study. European Journal of Operational Research, 156, 267-286.

Maciejowski, J.M., 1989. Multivariable feedback design. Wokingham: Addison-Wesley.

Morari, M. and Lee, J.H., 1999. Model predictive control: Past, present and future. Computers of Chemical Engineering, 23 (4-5), 667-682.

Neely, A., Gregory, M., and Platts, K., 1995. Performance measurement system design: A literature review and research agenda. International Journal of Operations and Production Management, 15 (4), 80-116.

Qin, S.J. and Badgwell, T.A., 2003. A survey of industrial model predictive control technology. Control Engineering Practice, 11 (7), 733-764

Skogestad, S., 2000. Self-optimizing control: The missing link between steady-state optimization and control. Computers in Chemical Engineering, 24, 569-575.

Skogestad, S., 2004. Near-optimal operation by self-optimizing control: from process control to marathon running and business systems. Computers and Chemical Engineering, 29, 127-137.

Suwignjo, P., Bititci, U.S., and Carrie, A.S., 2000. Quantitative models for performance measurement system. International Journal of Production Economics, 64 (1), 231-241.

Škrjanc, I., Blažič, S., Oblak, S., and Richalet, J., 2004. An approach to predictive control of multivariable timedelayed plant: stability and design issues. ISA Transactions, 43, 585-595.

Tatsiopoulos, I.P. and Panayiotou, N., 2000. The integration of activity based costing and enterprise modelling for reengineering purposes. International Journal of Production Economics, 66, 33-44.

Taylor, S.G., Seward, S.M., and Bolander, S.F., 1981. Why the process industries are different. Production and Inventory Management Journal, 22 (4), 9-24.

Veleva, V. and Ellenbecker, M., 2001. Indicators of sustainable production: framework and methodology. Journal of Cleaner Production, 9, 519-549. 